\title{
Here we are: Agriculture and Human Values in the Coronavirus (COVID-19) pandemic
}

\author{
Matthew R. Sanderson ${ }^{1}$
}

Accepted: 28 April 2020 / Published online: 2 May 2020

๑) Springer Nature B.V. 2020

To start, you are very likely among the more fortunate in our world if you are reading this article. Many people, including those now formally deemed 'essential'-nurses, doctors, grocery store clerks, farmworkers-will undoubtedly have much more urgent things to do. Among the many things that COVID-19 is making much clearer is who does the work of our agricultural and food systems, and who reaps most of the benefits.

This collection of articles is unorthodox for Agriculture and Human Values, or any scholarly journal for that matter. Agriculture and Human Values has developed into perhaps the leading international outlet for critical scholarly research on agriculture, food systems, and the values that shape them. Given the close connections between COVID-19 and our agriculture and food systems, I find it imperative in this moment to open conversations about these connections to a much broader cross-section of people living and working in agriculture and food systems than would normally contribute to Agriculture and Human Values. In this moment, Agriculture and Human Values can be a space to engage scholars, farmers, activists, eaters and others in the food system. We must not minimize the tremendous toll of COVID-19. Out of all the tragedy that is COVID-19, opportunities are emerging to re-imagine and re-work agriculture and food systems, perhaps in line with different values. This was the motivation for this collection.

But, how to do this? Could it be possible to pull together a collection of articles that was at least somewhat representative-of perspectives, of positions in food systems, of world region, etc.-given the tremendous scope of COVID-19?

This article is part of the Topical Collection: Agriculture, Food \& Covid-19.

Matthew R. Sanderson

mattrs@ksu.edu

1 Randall C. Hill Distinguished Professor of Sociology, Anthropology, and Social Work, Kansas State University, Manhattan, KS, USA
And, would it be even possible for potential authors to write at this time?

The response to my initial solicitations of authors was overwhelming, and truly inspiring. So many people, from so many places in the world, and from so many different vantage points agreed to contribute. And, so many agreed enthusiastically. I asked each author to write a very brief piece in the style of an essay for the public. I did not impose a particular theme for their article, other than to ask them to consider these questions: What should we learn from this terrifying, strange, unprecedented time? What does your work tell us about this time, the role(s) of agriculture and food systems in this time, and what we might do going forward?

I want to express my gratitude to the authors that contributed to this collection. They wrote briefly, which can be a difficult task, especially given the complexity of the topic (and, especially for academics more accustomed to 10,000word articles). They wrote for a public audience, with minimal referencing, and in the first person to the greatest extent possible (all of which can be quite difficult for academics). They wrote in-the-moment, without the benefit of hindsight. Many of the contributors based in the academy wrote despite their scholarly inclination to 'take the long view', and to 'stay above the fray'. They wrote on a short timeline, amidst all their other urgent and often much more important obligations. They wrote at the risk that their thoughts would seem dated by the time they were in print. They wrote with meaning and purpose.

There are countless angles from which to criticize this rather unorthodox collection, and any of these articles for that matter. At some point, there will likely be a time for more dispassionate, rigorous, scholarly critique and criticism. To read these articles from a more conventional academic approach, however, is to miss the point of this effort entirely. In this moment, I simply hope that you will suspend, for a time at least, some degree of judgment and merely consider each of these articles. 
Together, these essays form an ensemble of voices from different vantage points and different parts of the world. In these pages are conversations about agriculture and human values as seen through the lens of COVID-19. I hope these essays encourage us to reflect. I hope they help us see again, perhaps more clearly than before. As I write, many of the world's leaders are urgently trying to devise ways to 'get back to normal', as quickly as possible. I hope that these essays will help us consider how we might not get back to normal; how we might identify new paths to a new normal grounded in more sustainable, resilient, regenerative, just forms of agriculture than we had entering this crisis.

So, here we are. Here is Agriculture and Human Values in the midst of COVID-19. He we are nearly 100 years from the Spanish Flu pandemic, 90 years from the onset of the Great Depression and the Dust Bowl, 50 years after the first
Earth Day, and 50 years since Norman Borlaug was awarded the Nobel Peace Prize for his Green Revolution. What have we learned about agriculture and human values? What is COVID-19 revealing about agriculture, and our human values? Where to now? How? I hope these essays will at least foment conversations about these vital questions. I am convinced that there are answers in these essays, and more directly, in the process of engaging with these ideas in real, material ways.

Publisher's Note Springer Nature remains neutral with regard to jurisdictional claims in published maps and institutional affiliations. 